\title{
Structure Optimization Design for Brake Drum Based on Response Surface Met- hodology
}

\author{
Bin Zheng (ORCID: 0000-0003-2579-5316), Xin Wang (ORCID: 0000-0002-2656-4360), Jingdong Zhang \\ (ORCID: 0000-0002-3325-3501) \\ College of 'Transportation and Automobile Engineering, Panzhihua University, Panzhihua, 617000, China. E-mail: \\ zhengzhou4858@163.com
}

Taking a brake drum as the research object, the finite element method is used to analyze the dynamic characteristics and optimize its design. In order to increase the stiffness without increasing the weight of the brake drum, the main design parameters are tested by Box-Behnken experiment design. A threedimensional model of the brake drum is established by using SolidWorks software, and then the finite element model of brake drum is imported into ANSYS software to perform modal analysis. On the basis of modal analysis, three important dimensions of the brake drum are defined as the input parameters, and the drum weight, the first, second and third natural frequencies are defined as the output parameters. The response surface model between the input and output parameters is established by using DOE (Design of Experiment). Finally, the input parameters are optimized by multi-objective genetic algorithm and five Pare solutions are obtained. The fifth solution is chosen as the optimal solution based on the production technique. The weight of the brake drum does not change obviously after optimization, but the first, second and third natural frequencies increases by $13.07 \%, 8.92 \%$ and $12.73 \%$ respectively, which provides a new idea for the design and optimization of brake drum.

Keywords: Brake drum, Sensitivity analysis, Response surface model, Multi-objective optimization, Finite element analysis, Design of experiment

\section{Introduction}

The braking system is one of the key parts of automobile chassis system, and its performance directly affects the safety of car. The important component of the braking system is the brake drum. With the high speed and heavy load of the automobile, higher requirements are put forward for the performance. However, due to the bad working environment, assembly and application of the brake, the brake drum is prone to cracks and abnormal wear in use, which can cause damage to the vehicle and death of personnel. Thus, it is of great significance to design and optimize the structure of brake drum [1-3].

A lot of researches on the modal analysis of the drum brake have been conducted [4,5], and various methods and results have also been presented recently. Li Han-wu used the finite element method to compute the brake drum of an automobile drum brake [6]. By modifying the structural parameters and material parameters of the brake drum, the natural frequency range of various parts can be staggered and the vibration noise can be reduced. Taking DongFeng TD 485 drum brake as the research object, Li Nai-bin analysed the force of drum brake [7]. Three dimensional models of main components of the drum brake, such as brake drum, brake shoe and friction plate are established. The nonlinear analysis of friction contact of drum brake is carried out by ANSYS. The equivalent stress distribution and deformation of drum brake with small angular displacement are researched, which provides a reliable basis for the improvement design of the brake. Aiming at the vibration problem of brake drum during braking, the finite element method is proposed to optimize the brake drum. Through modal analysis of the brake drum, the natural frequency and vibration mode are obtained, and the resonance risk and design hidden trouble are carried out. On this basis, the structure optimization is carried out [8]. $\mathrm{Xi}$ Chuanpeng uses virtual prototype technology to study a brake. The virtual prototype model of brake is simulated by ADAMS software. Meanwhile, the finite element software ANSYS is used to analyse the surface stress of each friction plate. The influence of friction coefficient on the amplitude and frequency band of the brake was obtained [9]. In order to solve the squeal problem of disc brake and drum brake, Ibrahim Ahmed proposed a research method of brake squeal based on finite element method [10]. The natural frequency and mode shape of the brake are studied by the finite element method. Meanwhile, the squeal can be reduced by reducing the friction coefficient of the brake lining.

At present, most of the static and modal analysis of brake drums uses finite element methods, and there are few studies on the structural optimization of brake 
drums. Since the brake drum is an important part of the drum brake and, it is necessary to optimize the structure of the brake drum to ensure the driving safety.

Taking a brake drum as the research object, the modal analysis and optimization design are carried out by using the finite element method. In order to improve the dynamic characteristics of the brake drum, the central composite design experimental method is carried out. Moreover, on the basis of the experimental design, the sensitivity analysis of the design parameters is carried out and the response surface model is established. The multi-objective optimization algorithm is used to optimize the response surface model. Combined with the brake drum manufacturing process, the best optimization scheme is determined.

\section{Material and Methods}

\subsection{Structure of brake drum}

Automobile braking system has three main functions [11]. The first is to slow down or stop a moving car. The second is to keep the speed of cars going downhill stably. The third is to keep a stopped car still. The brake is a part of the braking system that is used to produce the force to hinder the car. The braking torque of the brake used in automobile comes from the friction between the working surface of the fixed parts and rotating parts. Friction brake is divided into disc brake and drum brake [12]. Drum brake is mainly composed of brake drum, brake plate, brake shoe (leading shoe and trailing shoe), brake wheel cylinder and return springs.

The physical picture of brake drum is shown in Figure 1.

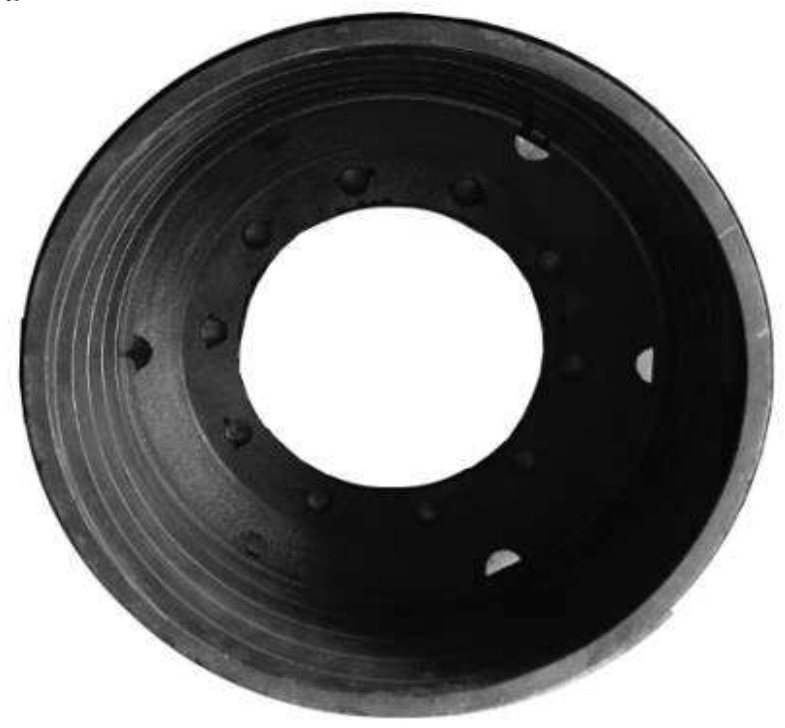

Fig. 1 Physical picture of brake drum

The three-dimensional model of brake drum is established by SolidWorks. Figure 2 shows the three-dimensional model of the brake drum.

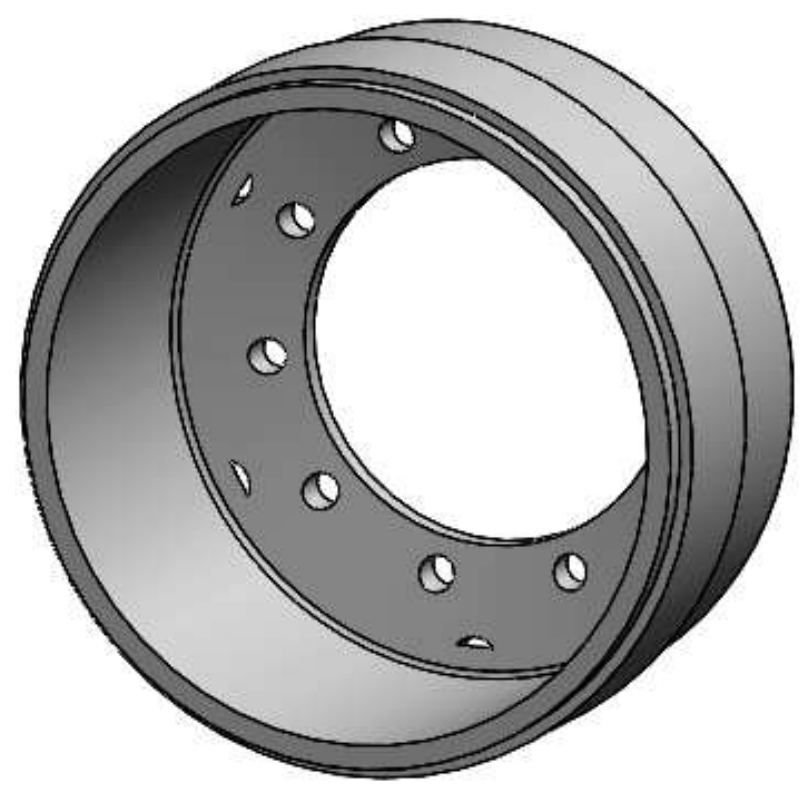

Fig. 2Three-dimensional model of brake drum

Gray cast iron is commonly used as the material of brake drum, which has good tensile strength, abrasion resistance and damping. In this paper, the gray cast iron used for brake drum is HT250, and its density is $7800 \mathrm{~kg} / \mathrm{m} 3$, elasticity modulus is $2.10 \mathrm{e}+11 \mathrm{~Pa}$ and Poisson ratio is 0.27 .

\subsection{Modal analysis of brake drum}

When the brake drum is meshed, the tetrahedron is used to generate meshes quickly and automatically. The tetrahedral mesh has the characteristic of equidirectional refinement. The size of the grid element is $6 \mathrm{~mm}$, the number of divided grid nodes is 331110 , and the number of grid elements is 194761 . Figure 3shows the finite element model of the brake drum.

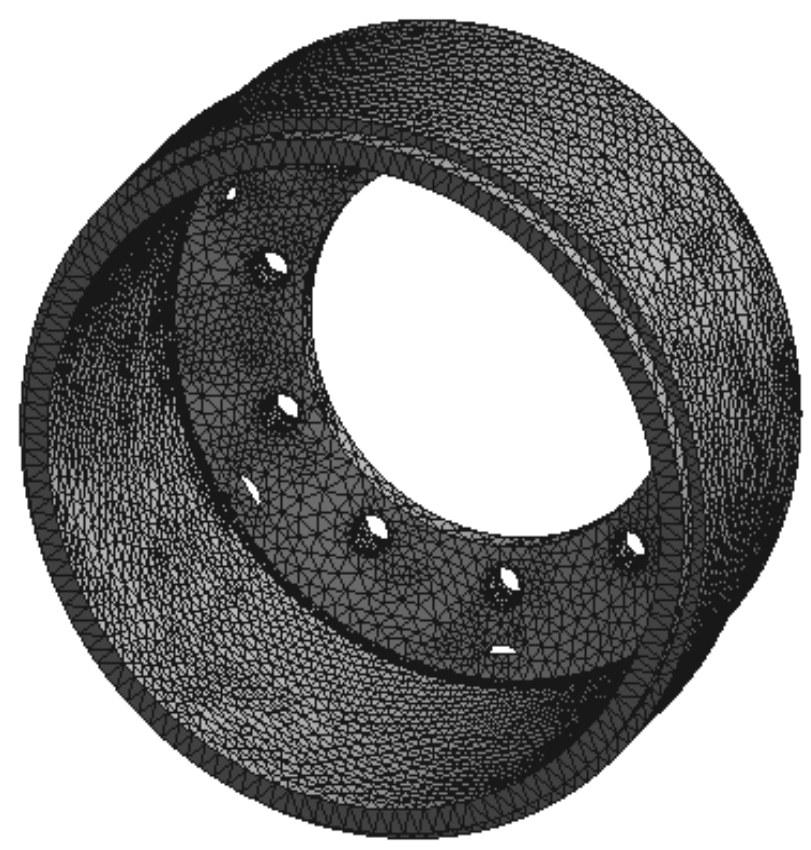

Fig. 3 Finite element model of brake drum 
Modal analysis is mainly used to determine the structural vibration characteristics [13]. It is the most basic and important type of structural dynamic analysis. It is usually used to solve the natural frequencies and modal vibration shapes of structures. Natural frequency and modal shape are one of the important parameters in the design of structures with dynamic loads. Modal analysis is the basic type of dynamic frequency domain analysis. Through the modal analysis of structure, resonance can be avoided in the structural design. ANSYS based modal analysis belongs to linear analysis, and there are seven modal analysis methods in ANSYS. They are Block Lanczos method, subspace, PCG Lanczos, super node, unsymmetric, damped and QR damped method. Modal analysis is carried out in ANSYS, including modelling, loading and solving, expanding modal, observing analysis results and post-processing. The dynamic analysis formula is shown in equation (1).

$$
[M]\{\ddot{x}\}+[C]\{\dot{x}\}+[K]\{x\}=\{F(t)\}
$$

Here, $[M]$ is the mass matrix; $[C]$ is the damping matrix, and $[K]$ is the stiffness matrix or coefficient matrix. When calculating the mechanical properties of finite element body, the stiffness matrix is a very important coefficient matrix that connects the force and deformation. $\{x\}$ represents the displacement vector. And $\{F(t)\}$ represents the force vector.

In undamped modal analysis, equation (1) does not consider the effect of damping, and then equation (1) degenerates to equation (2).

$$
[M]\{\ddot{x}\}+[K]\{x\}=0
$$

For the linear system, the form of the free vibration displacement solution is equation (3).

$$
\{x\}=\left\{\Phi_{i}\right\} \cos \omega_{i} t
$$

$\omega_{i}$ represents the $i^{t h}$ order natural vibration frequency. $\left\{\Phi_{i}\right\}$ represents the eigenvector of the $i^{\text {th }}$ order mode shape.

The vibration characteristic equation of the structure is obtained as equation (4).

$$
\left([K]-\omega_{i}^{2}[M]\right)\left\{\Phi_{i}\right\}=0
$$

There are several reasons for modal analysis of drum brake. Through modal analysis, the drum brake can avoid resonance, reduce noise and be safe and reliable. The deformation of the drum brake will aggravate the vibration of various parts of the car, accelerate the damage of these components, and shorten its effective working time. Brake drum is mounted on the connecting flange of the wheel hub by ten bolts. They are set as fixed supports. After setting the constraint conditions for brake drum, modal analysis can be carried out by using ANSYS. The analysis results show the distribution of vibration intensity and the weak area of brake drum. It provides the fundamental basis for the optimization design of brake drum. The first to six natural frequencies and the mode vibration shapes are computed by ANSYS. Table 1 shows the re-

\begin{tabular}{|c|c|c|}
\hline Order & Natural Frequency/Hz & Mode vibration shape descriptions \\
\hline 1 & 446.67 & $\begin{array}{l}\text { The brake drum is elliptical in the XY plane and has } \\
\text { four maximum deformations. }\end{array}$ \\
\hline 2 & 665.92 & $\begin{array}{l}\text { The brake drum is round in the XY plane and has two } \\
\text { maximum deformations. }\end{array}$ \\
\hline 3 & 894.79 & $\begin{array}{l}\text { The brake drum is triangular in the XY plane and has } \\
\text { six maximum deformations }\end{array}$ \\
\hline 4 & 1217 & The brake drum moves back and forth along $\mathrm{Z}$ axis. \\
\hline 5 & 1639 & $\begin{array}{l}\text { The brake drum is quadrilateral in the XY plane and } \\
\text { has eight maximum deformations. }\end{array}$ \\
\hline 6 & 1898 & The brake drum moves back and forth along $\mathrm{Z}$ axis. \\
\hline
\end{tabular}
sults of the first to sixth natural frequencies and mode vibrations of the brake drum.

Tab. 1 The first to sixth natural frequencies and mode vibrations of the brake drum

The first to the third mode vibration shapes of the brake drum are shown in Figure 4.Based on the calculation results, the first natural frequency of brake drum is more than $446.67 \mathrm{~Hz}$. The lower natural frequencies of the brake drum are mainly concentrated in $500 \mathrm{~Hz}$ $1000 \mathrm{~Hz}$, and the analyzed frequency is also within this range. Therefore, it needs to avoid these lower natural frequencies by optimization design. 


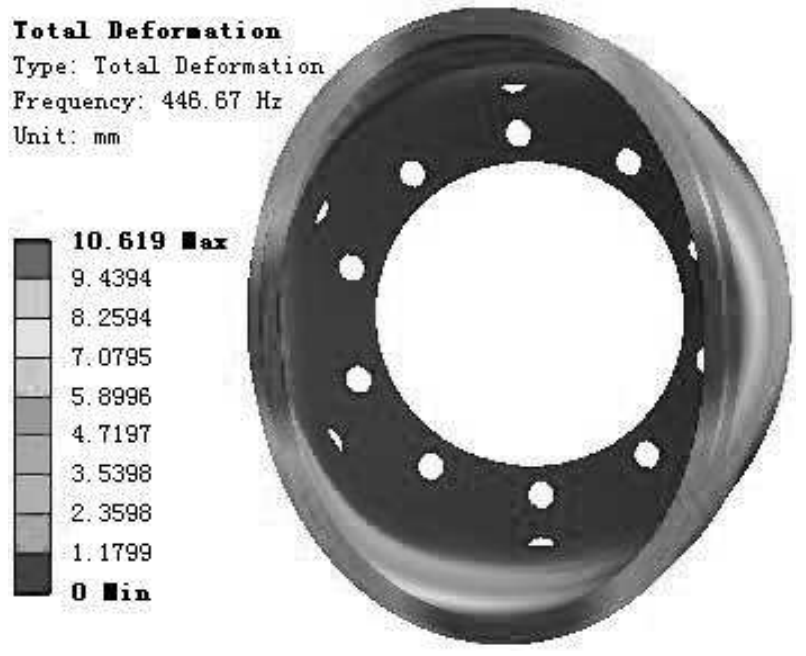

a) The first mode vibration

Total Deformation 2

Type: Total Deformation

Frequency: $665.92 \mathrm{~Hz}$

Unit: mm

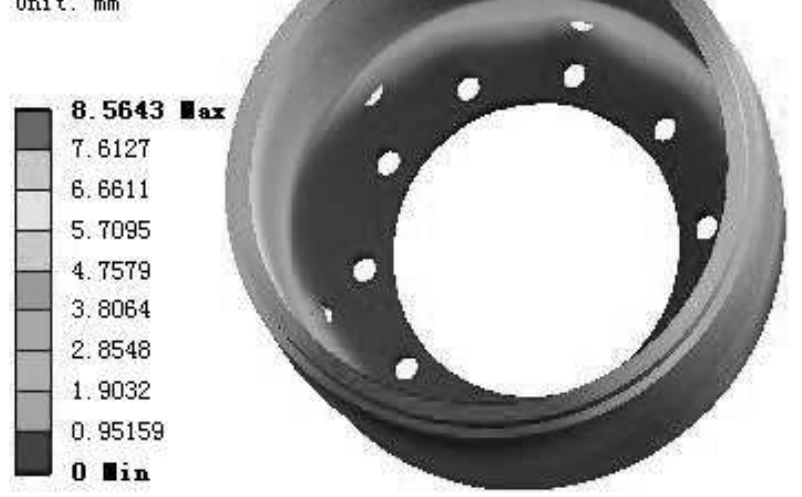

b) The second mode vibration

Total Deformation 3

Type: Total Deformation

Frequency: $894.79 \mathrm{~Hz}$

Unit: $\mathrm{mm}$

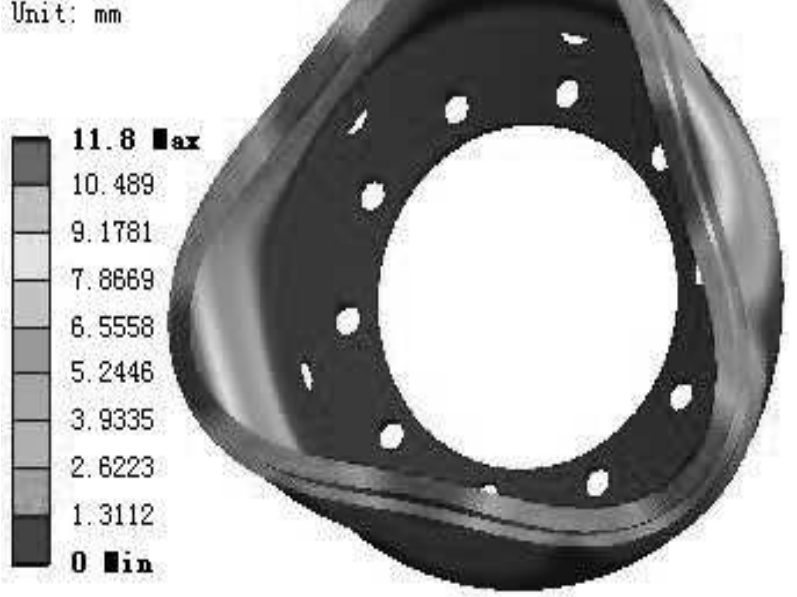

c) The third mode vibration

Fig. 4 The first to third mode vibration shape of brake drum

\subsection{Optimization design of drum brake}

The optimization design method is based on mathematical programming solution and the response surface model is established to optimize the dimensions of the brake drum. The specific optimization steps and procedures are summarized as follows.

Response surface methodology integrates the theoretical knowledge of mathematics and statistics. It uses reasonable experimental design methods and obtained corresponding data through experiments, and uses multiple quadratic regression method to simulate and calculate the relationship between design variables and output response [14].Response surface design includes experimental design, response surface model building, model adaptability checking, optimal combination scheme searching and more. The corresponding secondary response surface model is used to draw three-dimensional response surface and two-dimensional contour line, which can quickly obtain the corresponding response values under different elements. Furthermore, more and more prediction models are established for response surface design methods and good results are obtained.

The quadratic polynomial response surface model with $\mathrm{n}$ design variables is expressed as equation (5).

$$
y=\beta_{0}+\sum_{i=1}^{n} \beta_{i} x_{i}+\sum_{i=2}^{n} \sum_{j=1}^{i-1} \beta_{i j} x_{i} x_{j}+\sum_{i=1}^{n} \beta_{i i} x_{i}^{2}
$$

In equation(5), $y$ is the output response value; $\beta_{0}, \beta_{i}$, $\beta_{i j}$ and $\beta_{i i}$ are undetermined polynomial coefficients; $\beta_{0}$ is the constant; $\beta_{i}$ is the linear effect of design variable $x_{i} ; \beta_{i j}$ is the linear interaction effect between design variable $x_{i}$ and $x_{j}$; $\beta_{i i}$ is the quadratic effect of design variable $x_{i}$; and $n$ is the variable number of design.

In general, the probability of quadratic response surface modelling is $93 \%$, and there are too many design variables. Therefore, it is decided to adopt quadratic response surface modelling and take all quadratic terms, primary terms and the interaction between factors into consideration.

\section{Define design parameters of brake drum}

In the experimental design, the first thing is to set the range value of each size parameter, with reference to the provided parameter variation range.

The central composite design is used for the experimental design, with three design parameter variables and fifteen sample points. Considering the working condition of brake drum, the three dimension parameters $d_{1}, d_{2}$ and $d_{3}$ are selected as the design parameters as shown in Figure 7.

The initial value and variation range of design variables of brake drum is shown in Table 2. The modal characteristics of the brake drum are analyzed under the initial design parameters, and the obtained first, second and third natural frequencies are defined as the output parameters, they are $y_{1}, y_{2}$ and $y_{3} \cdot y_{0}$ was defined as the initial weight of the drum. Table 2 lists the design scheme and the final result of the experiment by using central composite design (CCD) method. 


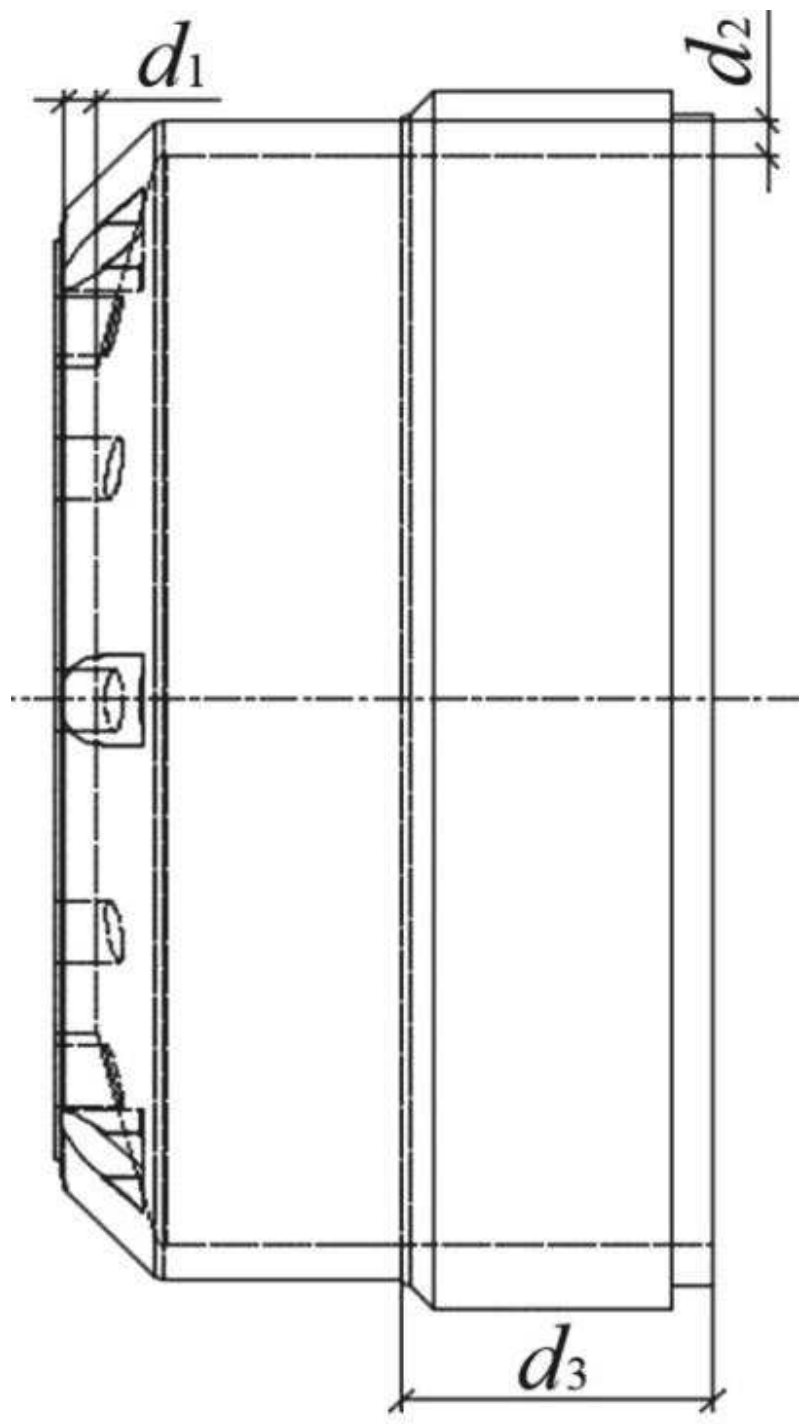

Fig. 7 Design parameters of brake drum
Tab. 2 Initial value and variation range of design parameters

\begin{tabular}{ccc}
\hline $\begin{array}{c}\text { Design para- } \\
\text { meters } / m m\end{array}$ & $\begin{array}{c}\text { Initial value / } \\
\mathrm{mm}\end{array}$ & $\begin{array}{c}\text { Variation range } \\
\text { of parameters } \\
\mathrm{mm}\end{array}$ \\
\hline$d_{1}$ & 10 & $9 \sim 11$ \\
$d_{2}$ & 15 & $13.5 \sim 16.5$ \\
$d_{3}$ & 100 & $90 \sim 110$ \\
\hline
\end{tabular}

Table 3 gives the design scheme and the final result of the experiment when the central composite test design method was used for the experiment design on the drum.

\section{Analysis of response surface methodology}

The sample points obtained in the experimental design are analyzed to some extent with input parameters and output parameters, and the relationship between the input parameters and output parameters of the brake drum is expressed in figure form, namely the response surface analysis method [15].It can be seen from Figure 8 that when the input parameters are $\mathrm{d}_{1}$ and $\mathrm{d}_{2}$ respectively, the change of the input parameters will increase the value of the first natural frequency $\left(y_{1}\right)$ of the brakedrum. It can be concluded form Figure 9 that when the input parameters are $d_{1}$ and $d_{2}$ respectively, the weight and the quality of the brake drum would change with the input parameters.

Through the above analysis and combined with the results of DOE experiment design, a parallel graph of sample parameters between input parameters and output parameters can be obtained, as shown in Figure 10. The corresponding input and output results of each group of sample points are clearly given in Figure10.

Tab. 3 CCD design scheme and experimental results

\begin{tabular}{|c|c|c|c|c|c|c|c|}
\hline \multirow[t]{2}{*}{ No. } & \multicolumn{3}{|c|}{ Factors $/ \mathrm{mm}$} & \multirow{2}{*}{$\frac{\text { Weight } / \mathrm{Kg}}{y_{0}}$} & \multirow{2}{*}{$\begin{array}{l}\text { First natural fre- } \\
\text { quency } / \mathrm{Hz} \\
y_{1}\end{array}$} & \multirow{2}{*}{$\begin{array}{l}\text { Second natural fre- } \\
\text { quency } / \mathrm{Hz} \\
y_{2}\end{array}$} & \multirow{2}{*}{$\begin{array}{c}\begin{array}{l}\text { Third natural } \\
\text { frequency } / \mathrm{Hz}\end{array} \\
y_{3}\end{array}$} \\
\hline & $d_{1}$ & $d_{2}$ & $d_{3}$ & & & & \\
\hline 1 & 9 & 15 & 100 & 27.8 & 457.6 & 684.6 & 929.9 \\
\hline 2 & 11 & 15 & 100 & 26.7 & 459.8 & 650.1 & 955.9 \\
\hline 3 & 10 & 13.5 & 100 & 28.9 & 456.7 & 718.7 & 904.0 \\
\hline 4 & 10 & 16.5 & 100 & 26.9 & 429.0 & 676.9 & 876.9 \\
\hline 5 & 10 & 15 & 90 & 28.7 & 488.0 & 694.0 & 982.4 \\
\hline 6 & 10 & 15 & 110 & 26.2 & 485.2 & 689.8 & 993.3 \\
\hline 7 & 9.1 & 13.7 & 91.8 & 29.4 & 435.1 & 682.7 & 880.7 \\
\hline 8 & 10.8 & 13.7 & 91.8 & 25.0 & 456.2 & 655.0 & 959.9 \\
\hline 9 & 9.18 & 16.2 & 91.8 & 26.6 & 453.5 & 709.9 & 916.2 \\
\hline 10 & 10.8 & 16.2 & 91.8 & 26.4 & 510.1 & 672.0 & 1051.6 \\
\hline 11 & 9.18 & 13.7 & 108.1 & 28.0 & 502.8 & 725.3 & 871.3 \\
\hline 12 & 10.8 & 13.7 & 108.1 & 27.4 & 417.8 & 647.8 & 829.3 \\
\hline 13 & 9.18 & 16.2 & 108.1 & 29.3 & 418.2 & 709.5 & 829.3 \\
\hline 14 & 10.8 & 16.2 & 108.1 & 28.8 & 463.9 & 659.9 & 952.9 \\
\hline 15 & 10 & 15 & 100 & 30.7 & 460.2 & 719.2 & 907.7 \\
\hline
\end{tabular}




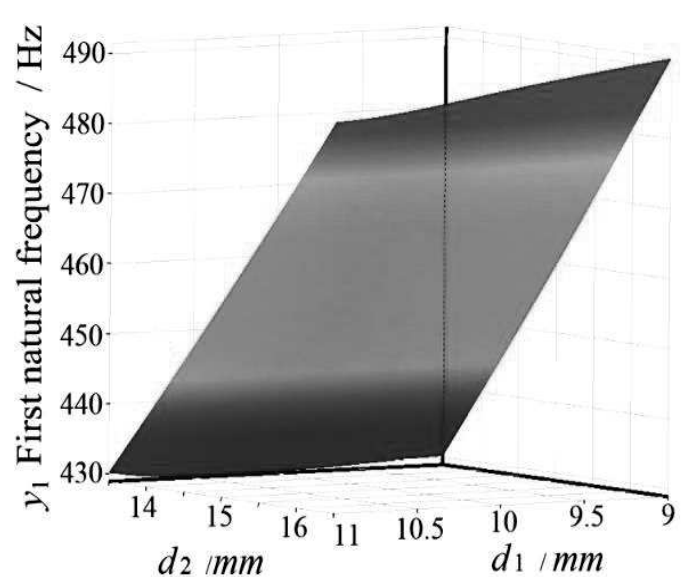

Fig. 8 Response surface curves of $d_{1}$ and $d_{2} v s y_{1}$

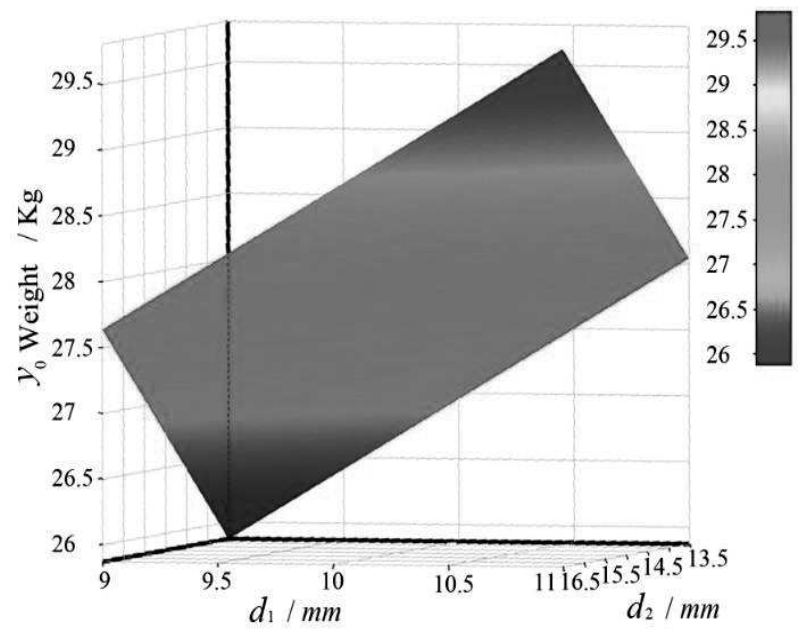

Fig. 9 Response surface curves of $d_{1}$ and $d_{2} v$ syo

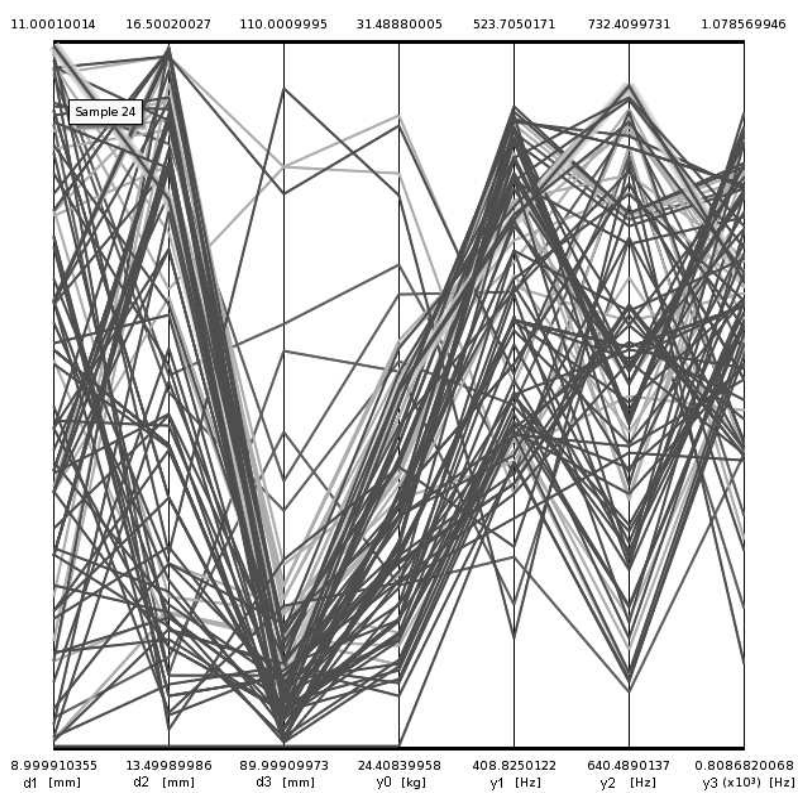

Fig. 10 Parallel graph of sample parameters

After the response surface analysis of the input and output parameters of the sample points, the sensitivity histogram of the natural frequencies of the three input parameters can be obtained as shown in Figure 11.

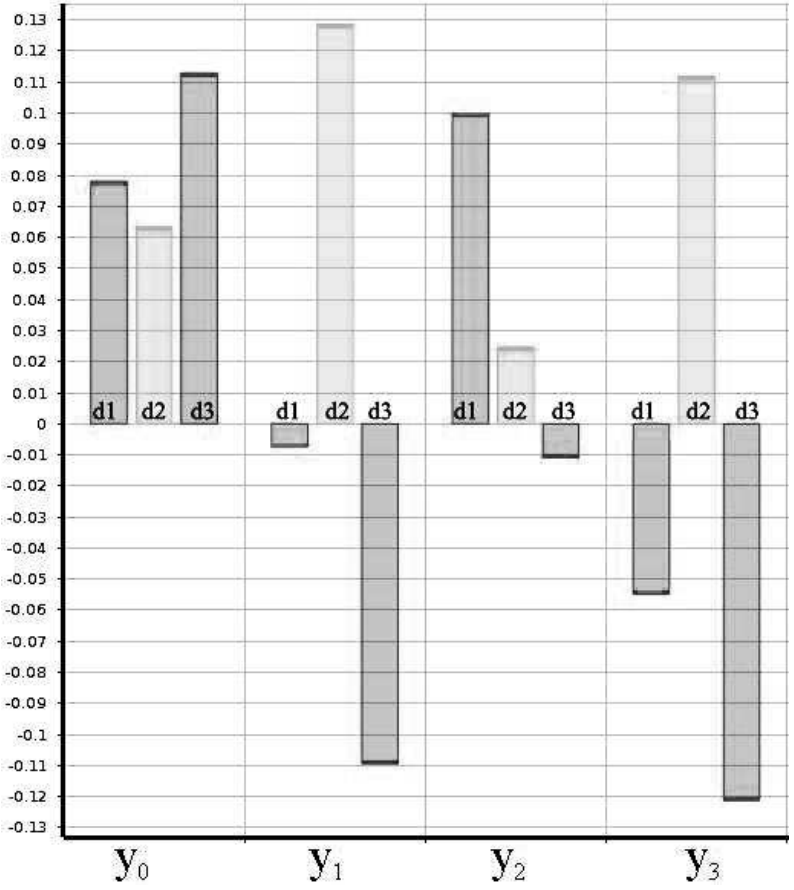

Fig. 11 Sensitivity analysis diagram of input parameters

By analyzing the values of each input parameter, it can be concluded that the changes of input parameters $d_{1}, d_{2}$ and $d_{3}$ have a certain impact on the weight and the natural frequency of brakedrum. Thus, a reasonable size change of these dimensional parameters can change the effect of natural frequency of the brake drum.

Comprehensively, the content of the structural size change of the brake drum must be appropriately designed in accordance with the principle of lightweight, not to reduce the quality of parts to improve the dynamic performance of the structural strength, but to reduce and increase the quality of the brake drum to improve the dynamic performance [17]. Therefore, an appropriate modification of the drum size is most important. Based on the establishment of response surface and sensitivity size analysis, the restraint setting and size optimization of the brakedrum structure can be performed. Taking the quality of the brake drum in the initial state as the constraint condition, at least make the optimized value of this variable equal to or less than the initial value [18].

\section{Results}

After fitting the response surface model, multi-objective optimization can be achieved by using MOGA (multi-objective genetic algorithm) in ANSYS Workbench [16]. MOGA is an algorithm based on NSGA-II (Non-dominated Sorting Genetic Algorithms II). It can be quickly optimized in a large space of design variables. It is suitable for calculating the global maximum or minimum value and can avoid the trap of local optimum. It can find the non-dominated 
solution through fast sorting, retaining the elite population and maintaining the diversity of the population. In this paper, MOGA algorithm is used to optimize the design parameters of the drum. The weight of brakedrum in the initial design state is set as a constraint condition, so that the optimized weight is not higher than the initial value. To maximize the first, second and third natural frequency, a series of Pareto optimal solutions are obtained through multi-objective genetic algorithm. In Figure 12, feasible points represent the feasible solutions.

The samples given in Figure 12 are all reasonable optimization solutions, which can be selected according to different requirements of output parameters. Five sets of local optimization solutions are given in
Table 4.

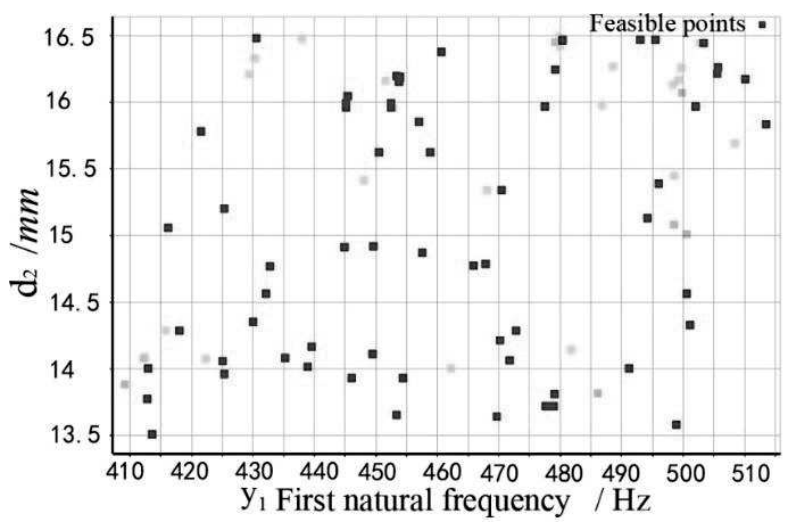

Fig. 12 The graph of Pareto set.

Tab. 4 Locally optimization solution

\begin{tabular}{lccccc}
\hline & Optimal set 1 & Optimal set 2 & Optimal set 3 & Optimal set 4 & Optimal set 5 \\
\cline { 2 - 6 }$d_{1} / \mathrm{mm}$ & 10.79 & 10.93 & 10.83 & 9.72 & 9.91 \\
$d_{2} / \mathrm{mm}$ & 16.26 & 16.17 & 16.06 & 16.1 & 16.38 \\
$d_{3} / \mathrm{mm}$ & 91.49 & 93.35 & 97.58 & 91.08 & 92.99 \\
$y_{0} / \mathrm{Kg}$ & 28.03 & 28.42 & 28.96 & 26.86 & 27.45 \\
$y_{1} / \mathrm{Hz}$ & 505.04 & 497.10 & 483.19 & 509.93 & 507.19 \\
$y_{2} / \mathrm{Hz}$ & 725.32 & 726.96 & 721.59 & 689.84 & 695.70 \\
$y_{3} / \mathrm{Hz}$ & 1008.66 & 989.11 & 959.63 & 1040.52 & 1027.42 \\
\hline
\end{tabular}

\section{Discussion}

The sample points given in Table 3 are all reasonable optimization solutions. According to different requirements of the output parameters, the resear- chers can choose among them. After analysis, the second set of sample parameters are selected as the optimization results and the manufacturing process requirements are considered comprehensively. The results of rounding the set of data are shown in Table 5.

Tab. 5 Design parameters comparison before and after optimization

\begin{tabular}{cccc}
\hline Design parameters $/ \mathrm{mm}$ & Before optimization $/ \mathrm{mm}$ & After optimization / mm & After rounding / mm \\
\hline$d_{1}$ & 10 & 10.79 & 11 \\
$d_{2}$ & 15 & 16.26 & 16 \\
$d_{3}$ & 100 & 91.49 & 92 \\
\hline
\end{tabular}

After comprehensive analysis, the fifth solution is finally selected as the optimal solution. After optimization, there is no significant change in the weight of brake drum, but its first, second and third natural frequencies are improved by $13.07 \%, 8.92 \%$ and $12.73 \%$ respectively, which can achieve the purpose of optimization.

\section{Conclusions}

Through the finite element modal calculation of brake drum, the natural frequencies and vibration mode can be obtained. On the basis of modal analysis and the design of experimental, the main design parameters of brake drum are optimized. Thus, the following conclusions can be obtained.

Based on the three-dimensional solid model created by SolidWorks and imported into ANSYS software, the finite element model is obtained, which has high modelling efficiency and saves a lot of modelling time. On the basis of modal analysis, three important dimensions of brake drum are defined as input parameters, and the weight, the first, second and third natural frequencies are defined as the output parameters. The response surface model between the input and output parameters is established according to the design of experiment. The input parameters are optimized by multi-objective genetic algorithm and five Pare solutions is obtained. The fifth solution is chosen as the optimal solution based on the production technique. The weight of brake drum does not change obviously after optimization, but the first, second and third natural frequencies are increased by $13.07 \%$, $8.92 \%$ and $12.73 \%$ respectively, which provides a new idea for the design and optimization of the brake drum. 


\section{Acknowledgements}

This research was supported by the Vanadium and Titanium Resources Comprehensive Utilization Key Laboratory of Sichuan Province (No.2018FTSZ32, No.2019FTSZ08) and Key Laboratories of Fine Chemicals and Surfactants in Sichuan Provincial Universities (No.2019JXY05).

\section{References}

[1] IBRAHIM A. (2012). Modeling of automobile drum brake for contact analysis using ANSYS. SAE, 2012-01-1810.

[2] WANG X.Y., FAN Z.J., WANG Q.C., et al. (2018). Experimental investigation and analysis on dynamic strain and temperature of drum brake. Engineering Mechanics, 35(10): 222-228.

[3] CHEN J., ZHANG Q., CHEN Y., et al. (2018). A research on thermal-flow two-way coupling analysis technique for drum brakes of commercial vehicles. Automotive Engineering, 40(5): 536541.

[4] LIU L. (2015). Study on the braking efficiency and optimal design of the drum brake in engineering automobile. Journal of Mechanical Transmission, 32(5):101-104.

[5] LIU K., PENG M.C., LIN Y.Q., et al. (2013). Finite element analysis of drum brake stamping-welding shoes based on ANSYS Workbench. Journal of Guangdong University of Technology, 30(1):92-96.

[6] LI H.W., DONG H.W. DU H.L., et al. (2011). Modal analysis of brake drum of automobile drum type brakes. Forestry Machinery \& Wood Working Equipment, 39(6):31-33.

[7] LI N.B., LI Y.P. (2017). Finite element analysis of the brake drum of rear drum brake based on ANSYS WORKBENCH. Value Engineering, (8):91-93.

[8] ZHANG J.D, ZHENG B., YAO J., et al. (2016). Modal analysis and optimization design on brake drum for a heavy-duty automobile. Bus \& Coach Technology and Research, (2): 1-3.

[9] XI C.P., WANG K. LI Z.X. (2017). Simulation analysis of a new type wheel brake of heavy duty truck. Joumal of Mechanical Transmission, 41(2):171-176.

[10] IBRAHIM A., SHAWKY A.S. (2006). On the analysis of drum brake squeal using finite element methods technique, SAE 2006-01-3467.

[11] XU Y.M., LI S.,RONG X.M. (2015). Composite structural optimization by genetic algorithm and neural network response surface modeling. Chinese Journal of aeronautics,18(4):310316.

[12] PARK S.J.,LEE C.M.,HWANG Y.K. (2011). Lightweight design of $45000 \mathrm{r} / \mathrm{min}$ spindle using full factorial design and extreme vertices design methods. Journal of central south university of technology,18(1):153-158.

[13] MA X., CHENG M.D., ZHAO X. (2012). Research of finite element analysis of drum brakes. Machinery Design \& Manufacture, (6):217219.

[14] WANG Y.L., WANGL.M., et al. (2015). Finite element analysis and investigations of the back case of a transmission with a central brake. Proceedings of the Institution of Mechanical Engineers, 229(12): 1611-1627.

[15] HONMANN C., SCHIFFNER K., OERTER K., etal. (1999). Contact analysis for drum brakes and disk brakes using ADINA. Computers and Structures, 72(1-3): 183-187.

[16] LI C., JIN J., YANG L.K. (2017). A comparative experimental study on thermal fade performance of disc and drum brakes. Automotive Engineering, 39(12): 1397-1401, 1430.

[17] FILIP HRDLICKA, MARTIN KRATOCHVIL, IVANA MAZINOVA, PAVEL FLORIAN (2019). Use of MaterialShape Factors in Mechanical Design. Manufacturing Technology, 19(3):397-403.

[18] DAVID KOREČEK, PAVEL SOLFRONK, JIŘÍ SOBOTKA (2020). Numerical Simulation as a Tool to Predict Sheet Metal Forming Process of TRIP Steel HCT690. Manufacturing Technology, 20(5):625-631. 